\title{
Setting priorities in healthcare institutions: The case of McGill University Health Centre
}

\author{
Onur Hisarciklilar ${ }^{1}$, Atish Woozageer ${ }^{2}$, Afrooz Moatari-Kazerouni ${ }^{1}$, Andrea Schiffauerova ${ }^{3}$, Vincent Thomson ${ }^{* 1}$ \\ ${ }^{1}$ Department of Mechanical Engineering, McGill University, Montreal, QC, Canada \\ ${ }^{2}$ Department of Mechanical and Industrial Engineering, Concordia University, Montreal, QC, Canada \\ ${ }^{3}$ Concordia Institute for Information Systems Engineering, Concordia University, Montreal, QC, Canada
}

Received: July 14, 2016

DOI: $10.5430 /$ jha.v5n6p38
Accepted: September 4, $2016 \quad$ Online Published: September 13, 2016

URL: http://dx.doi.org/10.5430/jha.v5n6p38

\begin{abstract}
Priority setting is a decision-making process concerning the distribution of resources. The imbalance between allocated resources and public demand for health services as well as the inherent complexity of healthcare institutions are making priority setting one of the most challenging health management issues. Nevertheless, the priority setting processes and policymaking have not been studied very much at the hospital strategic planning level, i.e., the prioritisation of clinical activities. The purpose of this paper is to provide an evidence based case for improving the priority setting process in large hospitals. In a qualitative case study carried out at the McGill University Health Centre (MUHC), a priority setting exercise is described and the process is assessed in line with an accountability for reasonableness framework. Data collection involved in-depth, one-on-one interviews with key participants, review of key documents, and in-field observation. To assess the priority setting exercise, this paper compares the priority setting process against the five conditions of accountability for reasonableness, and identifies good practices and opportunities for improvement.
\end{abstract}

Key Words: Priority setting, Accountability for reasonableness, Hospital

\section{INTRODUCTION}

Priority setting, also known as rationing or resource allocation, is a decision-making process concerning the distribution of resources, e.g., money, time, beds, drugs, among competing interests, such as institutions, programs, patients, services, diseases. ${ }^{[1]}$ Priority setting is one of today's most important health policy issues; the imbalance between allocated resources and public demand for health services as well as the inherent complexity of healthcare institutions make priority setting one of the most difficult issues faced by managers of these institutions.

In recent years, there have been empirical descriptions of pri- ority setting in various contexts. ${ }^{[2-13]}$ As examples, Weale ${ }^{[14]}$ provided a literature review and a conceptual discussion of the common themes emerging in the field of public and patient involvement and health priority setting. Smith et al. ${ }^{[15]}$ carried out in-depth case studies of six Canadian healthcare organizations to obtain from healthcare leaders their understanding of the concept of high performance in priority setting and resource allocation as well as the factors contributing to its achievement. Nevertheless, there has not been much research done at the hospital strategic planning level, i.e., prioritisation of clinical activities. Madden et al. ${ }^{[16]}$ evaluated priority setting in a network of three large university affiliated hospitals in Toronto. They focused only on Clinical

*Correspondence: Vincent Thomson, Prof.; Email: vince.thomson@mcgill.ca; Address: Department of Mechanical Engineering, McGill University, 817 Sherbrooke West, Montreal, QC, Canada. 
Activity Target Setting, the final component of the strategic planning process, with a spotlight on the use of an appeal process. On the other hand, Martin et al. ${ }^{[10]}$ examined a range of priority setting decisions for a hospital's strategic planning process during a priority setting exercise at a tertiary-care teaching hospital in Toronto. Barasa et al. ${ }^{[17]}$ conducted a thematic review of empirical studies to explore the factors that impact upon priority setting at the hospital level. Their findings suggested that priority setting exercises in hospitals were influenced by: (1) contextual factors such as decision space, resource availability, financing arrangements, availability and use of information, organizational culture and leadership; (2) priority setting processes that depend on the type of priority setting activity; (3) content factors such as priority setting criteria; and (4) actors, their interests and power relations.

Menon et al. ${ }^{[18]}$ described priority setting as four steps: (1) identification of health care needs, (2) allocation of resources, (3) communication of decisions to stakeholders, and (4) management of feedback from stakeholders. The leading conceptual framework for healthcare priority setting is the "accountability for reasonableness" by Daniels \& Sabin ${ }^{[19-21]}$ where legitimacy and fairness are two key goals for priority setting. Although developing fair deliberative processes is an essential piece of securing socially acceptable priority setting decisions, healthcare is characterized by significant differences in capacity for effective participation in the processes that shape these priorities. To overcome this, Sibbald, et al. ${ }^{[22]}$ expanded the framework based on empirical observations involving participant reported, priority setting values. The extended framework prescribes five success conditions to be met in order to achieve a legitimate and fair priority setting process: ${ }^{[22,23]}$ (1) stakeholder engagement, (2) explicit process, (3) information management, (4) consideration of values and context, (5) revision and appeal mechanism.

Interdisciplinary approaches are also available for priority setting practices. One example is program budgeting and marginal analysis (PBMA) by Mitton et al. ${ }^{[24,25]}$ The concept of PBMA is to ensure that opportunity cost and margin are evaded in the decision-making process. Mitton et al. ${ }^{[26]}$ presented a detailed step by step guide for carrying out a priority setting process based on the PBMA framework. Mitton et al. ${ }^{[27]}$ determined how resources within a surgical program in a Canadian rural hospital might be reallocated to better meet local community needs by using the PBMA process. Robinson et al. ${ }^{[28]}$ reported on a qualitative research study which investigated local priority-setting activity across five English Primary Care Trusts.

Accountability for reasonableness is an ethics approach that

Published by Sciedu Press focuses on ensuring fair processes, whereas PBMA is an economic approach to priority setting. Yet, there is no agreement that any one framework provides decision-makers with comprehensive advice on how to set priorities given limited resources.

\section{Research objectives}

This paper describes an exercise at McGill University Heath Centre (MUHC) to provide an evidence based case for improving priority setting in a large hospital. At the time of the study, costs continued to increase as a result of increasing patient volumes and the complexity of healthcare services. MUHC wanted to support research and healthcare services together in order to keep McGill at the leading edge of research discovery and healthcare practice; however, the budget did not allow developing excellence in all domains. Moreover, in 2008 the Quebec Ministry of Health asked MUHC to reorient its mission. These circumstances pushed MUHC to reprioritize its programmes and to declare its future orientation to MUHC stakeholders: governments, research granting agencies and the public.

This paper investigates the question of how to set up a work plan that is effective and structured in order to consider the strengths of clinical activities in a balanced and fair manner, where a priority setting exercise is used to differentiate services and programs within the framework of accountability for reasonableness for resource re-allocation.

\section{RESEARCH BACKGROUND: PREVIOUS PRIORITY SETTING ATTEMPT AT MUHC}

There was an unsuccessful priority setting exercise at MUHC in 2007-2008. An ad-hoc committee was created and undertook priority setting using five meetings to review MUHC's clinical programmes. The committee defined nine priority programmes. After communicating the results to MUHC stakeholders, serious concerns were expressed regarding the procedure that was followed and the staff involved. Indeed, the priority setting exercise was a top-down process and not all the stakeholders adhered to the method. The main criticisms were: (1) the choice of programs was incorrect, (2) some excellent programs were missed, (3) the priority setting process was flawed, (4) the analysis was not representative of the full spectrum of opinions, and (5) no distinction was made between adult and paediatric priorities. Nevertheless, there was a general agreement that a prioritization exercise was overdue and that the failure to complete the exercise would be damaging in the long term. This paper focuses on the analysis of a second exercise during 2009-2010. 


\section{RESEARCH APPROACH}

Priority setting at MUHC is described through a qualitative case study. A case study is an empirical inquiry which focuses on a contemporary phenomenon within a real-life context. It has been defined as being suitable for studying complex social phenomena. ${ }^{[29]}$

\subsection{Conceptual framework}

The priority setting exercise during 2009-2010 was mainly assessed against success conditions using the accountability and reasonableness framework. Drawing on the ethical conditions found in the accountability for reasonableness framework, it was decided to use this approach to ensure the process itself was fair and legitimate rather than other approaches such as PBMA, which only focus on value for money.

We performed our assessment based on the five conditions given by Sibbald et al. ${ }^{[22]}$ The reasons behind this were, firstly, they embrace the conditions described in the accountability for reasonableness framework. Secondly, they give a clear set of metrics for building an assessment. Thirdly, they were the ones that the Strategic Decision Committee at MUHC found comprehensive and were actually used in the priority setting process. The conditions are:

Stakeholder engagement: An organization should identify both the internal and external stakeholders and get them involved in the decision-making process.

Explicit process: The organization should make the decision-making process transparent to all stakeholders. Trust and confidence can be gained if the organization adheres to a predetermined process.

Information management: The organization should decide what information is available to decision-makers during the priority setting process, what information is used, and what information is perceived as lacking. Also, it should decide how the information is managed and collected.

Consideration values and context: The values of the organization, of the organization's staff, and of other stakeholders, which include: patients, policy makers, politicians and members of the community, are all important in a priority setting process. Context refers to the goals of the organization, which are stipulated in the organization's strategic plan.

Revision and appeal: Formal mechanisms of revision and appeal should be established so that decisions can be reviewed and any disagreements can be constructively addressed. The appropriate revision process should provide opportunities to introduce new information, to correct errors, and to remedy failures in the process, thereby enhancing decision quality.

\subsection{Data collection}

Data collection for an assessment of the priority setting process at MUHC involved three data sources: in-depth one-onone interviews, key documents, and in-field observation.

Ten interviews were conducted based on informationoriented snowball sampling. The MUHC Associate Director General for Medical Affairs and his associate were identified by virtue of their involvement in priority setting. They identified subsequent respondents who were perceived to be key participants in priority setting.

The interviews were conducted using an interview guide using open-ended questions that were based on the framework of the priority setting exercise and Sibbald's PhD thesis, ${ }^{[23]}$ which provided a guideline based on accountability for reasonableness. Respondents were asked to describe the priority setting process at the hospital management level, who were involved, what criteria were considered, what decisions and rationales were publicized, what were the opportunities for revision, and what were the mechanisms for enforcement.

The key documents that were reviewed included: minutes of the Strategic Decision Committee meetings, MUHC's strategic plan, and priority evaluation documents. Eight months of in-field observation were done during the process setting exercise. The key events that were observed were town hall meetings, Strategic Decision Committee meetings, Workgroup meetings, and clinical division question-and-answer sessions.

Reliability and consistency of information about the priority setting process were obtained by cross-referencing information obtained from interviews and process documents. Data gathering was a continuous exercise as the process unfolded. Interviews were re-conducted and other people interviewed to obtain a consistent view of the priority setting process. Due to the high level of consistency in terms of process data, interview information and participant opinions, the authors thought that the conclusions drawn about the priority setting exercise were valid.

\subsection{Data analysis strategy}

To develop a report of the priority setting exercise, the authors used in-field notes, all types of documents that emerged throughout the process, and respondent transcriptions from interview recordings. To assess the "goodness" of the priority setting, we compared the description in the report against a conceptual framework to identify areas of correspondence, which were considered good practices, as well as gaps, which were considered opportunities for improvement. 
We took three steps to ensure the validity of our findings: respondents from different levels of hospital management and professions were interviewed; interview data through the analysis of key documents were validated; and study findings were distributed to a number of respondents who confirmed their reasonableness.

\section{Case Study: Second PRIORIty SeT- TING EXERCISE AT MUHC}

At the time of conducting this research, the MUHC had 63 clinical divisions. MUHC was under constant pressure to provide a large range of services without additional budgetary allocation. In this arrangement, all flexibility in discretionary financing of programmes was removed, and the likelihood of any programme achieving national or international excellence was compromised. Thus, there was an explicit contradiction between the expectation of the Quebec Ministry of Health and Social Services for MUHC to provide care for all, and the insistence that the hospital reorient its mission towards tertiary care programmes. Choices had to be made about where to focus effort. Therefore, the second priority setting exercise occurred between May 2009 and September 2010. The proposal for the second exercise stemmed from the comments received from the first exercise.

An organisation with multiple specialized work groups was set up to maximize stakeholder involvement and to ensure a fair and transparent process, including the Strategic Decision Committee, Workgroup, and a Support Team.

The framework and selection criteria were determined through a series of meetings with the heads of the 63 clinical divisions as well as other MUHC constituents. A workbook tool was created to evaluate clinical activities. Before all the clinical divisions were asked to put the required information into a workbook, the Strategic Decision Committee tested its content through a beta testing campaign. Subsequent to the beta testing, the workbook was sent to clinical division heads for comment. Workbooks from 86 clinical activities were submitted for consideration by the 63 clinical divisions. Three days of "retreat period" were planned to undertake the evaluation. These dedicated days gathered Strategic Decision Committee members and Mission executives for an intensive effort to finalize the priority determination. The preliminary list of priorities was posted on the MUHC intranet, and the stakeholders were invited to review the results and to provide comments for an eventual revision.

\subsection{Organization of executive teams}

The Strategic Decision Committee carried out the priority setting exercise and elicited feedback from the hospital community. The mandate of the committee was to execute the evaluation exercise such that it would meet the expectations and standards of the different parties involved within MUHC. The Strategic Decision Committee was responsible for deciding the allocation priorities. It determined the MUHC mission and values, set a list of evaluation criteria, developed an evaluation tool based on decision-making criteria, and established the list of priority programs grounded on stakeholder feedback.

In addition to the Strategic Decision Committee, a Workgroup was created. The members of the Workgroup were representatives from key administrative sectors such as Finance, Operations, Quality, Communications, Information Technology (IT), Nursing, and Planning. The main activity of the group was to support the Strategic Decision Committee during the priority setting exercise through development of support mechanisms, e.g., checking the completeness of collected data, evaluation tools, financial analysis, and ensuring that clinical data was analyzed from various business perspectives. The main functions of the Workgroup were:

(1) to assist in the validation of the information submitted by the clinical areas;

(2) to work collaboratively on the development of decision-making tools to support the selection of priorities:

(3) to determine the impact of the shift in resource allocation on the different clinical divisions; and

(4) to assist and develop a framework for on-going program evaluation with a 3-5 year cycle.

\subsection{Selection of evaluation criteria}

The Strategic Decision Committee and the Workgroup looked at evaluation exercises at other academic health centres and considered the criteria that were used. The first point considered was the vision, mission and values of the organization. Several mechanisms from different health centres were analyzed to see how they aligned their vision and values during priority setting exercises. Six evaluation criteria were selected, which were all considered equally important in the evaluation of any clinical activity.

\subsection{Data collection from clinical divisions}

The Strategic Decision Committee produced a workbook to gather information on a range of clinical, educational and research activities currently underway and planned over the next 5 years. The workbook also allowed clinical service leaders to self-assess their current and future plans against the criteria that were being used by the Strategic Decision Committee.

The workbook criteria were aligned with MUHC's vision and values. For each criterion, a series of questions were 
developed, where clinical divisions were asked to self-score their performance in a 1 to 9 range (1-3 low, 4-6 moderate, $7-$ 9 high). Table 1 summarizes different parts of the workbook and the data that was expected to be collected.

The workbook submission period began with a series of meetings including town hall and face-to-face meetings with various stakeholders, where the exercise, the various parts and questions in the workbook, and the recommendations for their completion were presented. Subsequently, the workbooks were electronically sent to department and clinical division heads. Nevertheless, all professional groups concerned in the delivery of clinical care were required to be involved in their completion.

Table 1. Parts of the workbook and their objectives

\begin{tabular}{|c|c|c|}
\hline Criterion & Description & Related MUHC Vision, Mission and Values \\
\hline Strategic Fit & $\begin{array}{l}\text { Positions or has the potential to position the MUHC as one of the } \\
\text { world's foremost academic health centres. }\end{array}$ & $\begin{array}{l}\text { Exceptional and integrated patient-centric care, } \\
\text { research and teaching: the MUHC is one of the } \\
\text { world's foremost academic health centres that } \\
\text { is highly committed to its community. }\end{array}$ \\
\hline $\begin{array}{l}\text { MUHC mandate: } \\
\text { Academic Health } \\
\text { Centre }\end{array}$ & $\begin{array}{l}\text { How teaching, research and innovation activities relate to } \\
\text { (e.g., are dependent upon, improve) the clinical activity. }\end{array}$ & $\begin{array}{l}\text { Creating value from our knowledge and } \\
\text { practice, leading education and training, } \\
\text { stimulating innovation and discovery }\end{array}$ \\
\hline $\begin{array}{l}\text { Healthcare } \\
\text { Context/ } \\
\text { Positioning }\end{array}$ & $\begin{array}{l}\text { This identifies the unique position of the MUHC in the Quebec } \\
\text { network of hospitals. It is characterized by the development of } \\
\text { collaborative relationships and it recognises regional or provincial } \\
\text { designations. It measures the volume of clinical activity in } \\
\text { comparison to other institutions both inside and outside MUHC. }\end{array}$ & $\begin{array}{l}\text { Exercising leadership in a networked } \\
\text { environment }\end{array}$ \\
\hline $\begin{array}{l}\text { Integrated } \\
\text { Complex Care }\end{array}$ & $\begin{array}{l}\text { This measures two key components that are involved in complex } \\
\text { care delivery: } \\
\text { - inter-professional collaborations, e.g., multidisciplinary teams. } \\
\text { - interdependent care, e.g., transitions from paediatrics to adult or } \\
\text { cross-discipline care (cardiac sciences). }\end{array}$ & $\begin{array}{l}\text { Exercising leadership in a networked } \\
\text { environment }\end{array}$ \\
\hline Clinical Impact & $\begin{array}{l}\text { This category measures: } \\
\text { - the volume of patient care by level of complexity. } \\
\text { - the impact of the activity on other clinical services. } \\
\text { - the uniqueness of the clinical activity. }\end{array}$ & $\begin{array}{l}\text { Providing the safest and highest quality care } \\
\text { and service. } \\
\text { Ensuring patients and their families remain the } \\
\text { top priority. }\end{array}$ \\
\hline $\begin{array}{l}\text { Sustainability (HR, } \\
\text { Fundraising, etc.) }\end{array}$ & $\begin{array}{l}\text { This measures the clinical activity in terms of human resources } \\
\text { (including number, attraction and retention issues), budget sources } \\
\text { (e.g., fundraising) and currently required technology and clinical } \\
\text { support. }\end{array}$ & $\begin{array}{l}\text { Valuing productivity and cost-effectiveness. } \\
\text { Attracting and retaining the best people. }\end{array}$ \\
\hline
\end{tabular}

"The McGill University Health Centre is located in the city of Montreal, Quebec, Canada, where each province has the mandate to fund and manage its healthcare sector

\subsection{Clinical activity evaluation and decision-making}

Following the completion and submission period, the Workgroup reviewed and validated the submitted workbooks. Three days were spent to determine a compliance level for each question in each workbook with regard to both the data and the clinical content. A standard evaluation tool was developed to allow the Workgroup to do the compliance check according to objective criteria and a common scoring system. Then, the Strategic Decision Committee members and Mission executives gathered in an intensive effort to finalize the priority determination, where, after overview presentations by the Mission executives, the Strategic Decision Committee identified strong elements and emerging themes, separated the workbooks into high, medium and low performers, and came up with a list of priorities. For each criterion in each workbook, the Strategic Decision Committee evaluated the consistency between the content of responses and the self- scores by the clinical division. If these two items were found to be inconsistent, the scores were updated. Instead of allocating a cumulative score, i.e., a sum of all criterion scores for each workbook and grouping the workbooks based on these scores, the Strategic Decision Committee did their assessment case-by-case for each workbook, and achieved a decision based on their overall appreciation.

\section{FINDINGS: ASSESSMENT OF THE PRIOR- ITY SETTING EXERCISE}

The assessment of the priority setting exercise was based on the five process elements for successful priority setting developed by Sibbald ${ }^{[23]}$ and discussed below.

\subsection{Stakeholder engagement}

Gibson et al. ${ }^{[30]}$ stated that stakeholders in a clinical priority setting exercise should include, at a minimum, adminis- 
trators, clinicians, members of the public and patients. In MUHC's case, the stakeholders that were actively involved in the process were administrators and clinicians. The strategy that the Strategic Decision Committee followed for ensuring the engagement of these stakeholders was to systematically inform them about milestone decisions during the process, and to organize meetings to gather their advice on the priority setting exercise and subsequent decisions. Throughout the process, there was continuous multidirectional feedback from involved stakeholders. The aim was to increase the level of interest in understanding the purpose and expected end results of the exercise.

\subsection{Explicit process}

The Strategic Decision Committee used numerous ways to communicate the details of the priority setting exercise and its results to stakeholders. These included email, town hall meetings, face-to-face meetings, memos, MUHC intranet and the workbook itself. This ensured continuous information sharing among the stakeholders, which made the decision-making transparent and enhanced stakeholder confidence in the exercise.

\subsection{Information management}

Different channels were used to collect the required data. The Support Team helped the Strategic Decision Committee in the analysis of the workbooks: collecting information on specific domains, obtaining budgetary information for each clinical division and mission, validating the workbooks, and verifying the quality of their content. The Workgroup also assisted the Strategic Decision Committee in developing decision-making tools to support the selection of priorities. These included compliance checking tools for workbooks, scorecards for workbook assessment, and tools to standardize data collection and decisions.

\subsection{Consideration of values and context}

From the very beginning, the Strategic Decision Committee and the Workgroup strained to find a framework for the priority setting exercise that would align with MUHC's vision and values. Each criterion proposed for the workbook was developed with respect to the context and vision of the organization.

The ultimate objective of a priority setting exercise was to guide institutional resource allocation. Therefore, tight collaboration between the Strategic Decision Committee and MUHC management board was required in order to put executive decisions concerning resource allocation into action. To this end, numerous meetings and information sessions were organized between the Strategic Decision Committee and MUHC management board to ensure that the organization's goals within the healthcare environment were articulated according to its strategic directions.

\subsection{Revision and appeal}

The revision process was seen as an opportunity to add to the overall information available to decision-makers, and to serve as a second check on the interpretation of information. It was considered to be a quasi-judicial "appeal" process to enhance the overall perception of fairness. The requests for review were made in writing and included all required information as well as evidence or argumentation to support the request. A common template was provided for all written submissions.

The team or team leader requesting a review was required to make a presentation to the Strategic Decision Committee summarizing the key points in the written submission. The Strategic Decision Committee followed up with questions, and then, considered the request in camera. After a full deliberation, the Strategic Decision Committee decided whether and in what way recommendations would be amended. Twenty-seven requests for revision were received and 21 revisions were performed. Seven revisions led to significant changes in the final decision, i.e., a shift in the prioritization of the revised clinical activity, which was due to a better explanation of the data previously provided in the workbook, or new information that was relevant to the decision criteria.

\section{DisCUSSION OF PRACTICE IMPLICATIONS}

At the end of the priority setting exercise, the Strategic Decision Committee identified approximately $50 \%$ of the 86 clinical activities as high performers, $35 \%$ as medium performers, and $15 \%$ as low performers. Moreover, $75 \%$ of the clinical divisions identified some undertakings that should be reduced or divested. When the authors wrote this paper on the priority setting exercise, several clinical activities were already reduced as prescribed in the exercise outcomes, and one activity was in the process of being completely divested.

When the list of prioritized clinical activities, identified during the second priority setting exercise, was compared to the first exercise, only minor differences were observed. Indeed, as observations and interviews confirmed, the success of the second priority setting exercise lay in the general satisfaction of the stakeholders with the way the exercise was performed. However, the improved process of the second priority setting exercise did provide more in depth information and an overall better evaluation of MUHC's clinical activities. When interviewing the heads of clinical divisions, Mission executives, and members of the Strategic Decision Committee, Workgroup, and Support Team, there was considerable agree- 
ment on the process, fairness and value of the priority setting exercise. This was insightful given the general dissatisfaction with the first priority setting exercise. It was observed that the second priority setting exercise was more inclusive; it differentiated adult care from paediatric care, and took into consideration innovative clinical and educational programs regardless of their size. When considering the extent to which the exercise gave decision-makers the ability to make better decisions, significant differences between the two attempts were observed. In the second exercise, data were collected based on a series of objective and comparable criteria as designed in the workbook. Decisions were made based on extensive data that were collected from all clinical divisions, and whose completeness and quality were approved by a multi-disciplinary team. Besides, data were improved through the appeal mechanism, where a large number of corrections were achieved.

The main enablers of success of the second attempt were:

(1) an increased focus on engaging a large spectrum of stakeholders into the data gathering and decisionmaking process;

(2) a significant effort to make the process and its outcomes explicit;

(3) an effective information management strategy achieved through dedicated teams for data gathering and analysis, and multiple tools that were used to organize and synthesize data;

(4) a data acquisition and analysis process that accurately considered MUHC's context and vision; and

(5) the implementation of a revision mechanism that was effective towards remedying misinterpretations and refining decisions.

Although the priority setting procedure and lessons learned benefited both researchers and practitioners in similar contexts, the implementation process presented significant challenges towards materializing outcomes. Managers who need to set priorities for activities in complex organizations can increase the quality of outcomes by considering the following strategies:

(1) adopt a unified business model for all activities or group activities that have the same structure or business imperatives;

(2) set common quality metrics for all units;

(3) build communication mechanisms such that all units are aware of each other's management practices and business models;

(4) consider business imperatives along with desired activity outcomes; and
(5) use the accountability for reasonableness framework when making decisions.

\section{Shortcomings of study}

The priority setting exercise was challenging in a large institution like MUHC, where there were very diverging business models and ways of measuring the quality of clinical activities. Consequently, finding common values that represented all clinical activities and produced generic representation of data were non-trivial tasks.

Criticism was raised about the poor timing of the announcement of the evaluation procedure. The evaluation procedure was not designed and announced until after the design of the workbook was completed. This delay created uncertainty when deciding on the right information to put into the workbooks. There was also uncertainty concerning what information the Strategic Decision Committee considered in defining MUHC values as no reference program was presented.

Furthermore, issues emerged concerning information management regarding the availability and quality of the required data from clinical divisions. There was indeed a lack of common quality metrics within clinical divisions to enable measuring how norms were being met.

\section{Conclusions}

This paper evaluated the priority setting process at MUHC to select a number of clinical activities, which through preferential allocation of resources would be allowed to develop. These priority areas would guide institutional resource allocation and would help to define the MUHC's position and role as the major academic centre in a network of institutions.

We conclude that, according to the framework's criteria, the exercise was a success. The collected information gave decision-makers the ability to effectively evaluate clinical activities and to make good decisions. Moreover, the priority setting process was perceived equitable, and there was a general satisfaction from stakeholders with the way the exercise was performed. The exercise was however challenging because of the very diverging business models in the various clinical divisions and the different ways of measuring the quality of clinical activities.

In this article we gave strategies for improving priority setting for activities in complex organizations, which involve adopting a unified model, setting common quality metrics, creating proper communication mechanisms, and balancing business needs with desired clinical outcomes.

\section{CONFlicts OF INTEREST Disclosure}

The authors declare they have no conflicts of interest. 


\section{REFERENCES}

[1] McKneally MF, Dickens BM, Meslin EM, et al. Bioethics for clinicians: 13. Resource allocation. Canadian Medical Association Journal. 1997; 157(2): 163-167. PMid: 9238146.

[2] Toms B. Priority-Setting in a Hospital Emergency Department: A Case Study. Asian Bioethics Review. 2015; 7(3): 321-330. http: //dx.doi.org/10.1093/heapol/czu010

[3] Tong A, Chando S, Crowe S, et al. Research priority setting in kidney disease: a systematic review. American Journal of Kidney Diseases. 2015; 65(5): 674-683. http://dx.doi.org/10.1053/j.ajkd. 2014.11 .011

[4] Gilson L, Doherty J, Lake S, et al. The SAZA study: implementing health financing reform in South Africa and Zambia. Health policy and planning. 2003; 18(1): 31-46. http://dx.doi.org/10.1093 /heapol/18.1.31

[5] Ham C, McIver S. Contested decisions: priority setting in the NHS. King's Fund. 2000.

[6] Kovac M. Rationing of hospital services in the Australian health system. Croatian Medical Journal. 1998; 39: 339-345. PMid: 9740647.

[7] Norheim O. Procedures for priority setting and mechanisms of appeal in the Norwegian health care system. Presentation at. $3^{\text {rd }}$ International conference on priorities in health. Amsterdam, The Netherlands. 2000.

[8] Hope T, Hicks N, Reynolds DJM, et al. Rationing and the health authority. British Medical Journal. 1998; 317(7165): 1067. PMid: 9774299. http://dx.doi.org/10.1136/bmj.317.7165.1067

[9] Maluka S, Kamuzora P, San Sebastiån M, et al. Decentralized health care priority-setting in Tanzania: evaluating against the accountability for reasonableness framework. Social science \& medicine. 2010; 71(4): 751-759. http://dx.doi.org/10.1016/j.socsc imed.2010.04.035

[10] Martin D, Shulman K, Santiago-Sorrell P, et al. Priority-setting and hospital strategic planning: a qualitative case study. Journal of Health Services Research \& Policy. 2003; 8(4): 197-201. http://dx.doi .org/10.1258/135581903322403254

[11] Kapiriri L, Martin DK. Priority setting in developing countries health care institutions: the case of a Ugandan hospital. BMC Health Services Research. 2006; 6(1): 1. http://dx.doi.org/10.1186/1 472-6963-6-127

[12] Mielke J, Martin DK, Singer PA. Priority setting in a hospital critical care unit: qualitative case study. Critical Care Medicine. 2003; 31(12): 2764-2768. PMid: 14668612. http://dx.doi.org/10. 1097/01.CCM. 0000098440.74735.DE

[13] Kapiriri L, Norheim OF, Heggenhougen K. Public participation in health planning and priority setting at the district level in Uganda. Health policy and planning. 2003; 18(2): 205-213. http://dx.doi .org/10.1093/heapol/czg025

[14] Weale A, Kieslich K, Littlejohns P, et al. Introduction: priority setting, equitable access and public involvement in health care. Journal of Health Organization and Management. 2016; 30(5): 736-750. http://dx.doi.org/10.1108/JHOM-03-2016-0036

[15] Smith N, Mitton C, Hall W, et al. High performance in healthcare priority setting and resource allocation: A literature-and case studybased framework in the Canadian context. Social Science \& Medicine.
2016; 162: 185-192. http://dx.doi.org/10.1016/j.socscim ed. 2016.06 .027

[16] Madden S, Martin DK, Downey S, et al. Hospital priority setting with an appeals process: a qualitative case study and evaluation. Health Policy. 2005; 73(1): 10-20. http://dx.doi.org/10.1016/j.h ealthpol.2004.11.002

[17] Barasa EW, Molyneux S, English M, et al. Setting healthcare priorities in hospitals: a review of empirical studies. Health policy and planning. 2015; 30(3): 386-396. http://dx.doi.org/10.1093 /heapol/czu010

[18] Menon D, Stafinski T, Martin D. Priority-setting for healthcare: who, how, and is it fair?. Health Policy. 2007; 84(2): 220-233. http://dx.doi.org/10.1016/j.healthpol.2007.05.009

[19] Daniels N, Sabin J. Limits to health care: fair procedures, democratic deliberation, and the legitimacy problem for insurers. Philosophy \& public affairs. 1997; 26(4): 303-350. http://dx.doi.org/10.11 $11 / j .1088-4963.1997 . t b 00082 . x$

[20] Daniels N, Sabin J. The ethics of accountability in managed care reform. Health affairs. 1998; 17(5): 50-64. http://dx.doi.org/1 $0.1377 /$ hlthaff .17 .5 .50

[21] Daniels N, Sabin JE. Setting limits fairly: learning to share resources for health. Oxford University Press; 2008.

[22] Sibbald SL, Singer PA, Upshur R, et al. Priority setting: what constitutes success? A conceptual framework for successful priority setting. BMC health services research. 2009; 9(1): 1. http: //dx.doi.org/10.1186/1472-6963-9-43

[23] Sibbald SL. Successful priority setting: a conceptual framework and an evaluation tool (Doctoral dissertation, University of Toronto). 2008.

[24] Mitton C, Donaldson C. Twenty-five years of programme budgeting and marginal analysis in the health sector, 1974-1999. Journal of Health Services Research \& Policy. 2001; 6(4): 239-248. http://dx.doi.org/10.1258/1355819011927558

[25] Mitton CR, Donaldson C. Setting priorities and allocating resources in health regions: lessons from a project evaluating program budgeting and marginal analysis (PBMA). Health Policy. 2003; 64(3): 335348. http://dx.doi .org/10.1016/S0168-8510(02)00198-7

[26] Mitton C, Donaldson C. Health care priority setting: principles, practice and challenges. Cost effectiveness and resource allocation. 2004; 2(1): 1. http://dx.doi.org/10.1186/1478-7547-2-3

[27] Mitton C, Donaldson C, Shellian B, et al. Priority setting in a Canadian surgical department: a case study using program budgeting and marginal analysis. Canadian Journal of Surgery. 2003; 46(1): 23 PMid: 12585790.

[28] Robinson S, Williams I, Dickinson H, et al. Priority-setting and rationing in healthcare: evidence from the English experience. Social Science \& Medicine. 2012; 75(12): 2386-2393. http://dx.doi.o rg/10.4103/1119-3077.104529

[29] Robson C. Real world research: A resource for social scientists and practitioners-researchers. Massachusetts: Blackwell Pushers; 1993.

[30] Gibson JL, Martin DK, Singer PA. Setting priorities in health care organizations: criteria, processes, and parameters of success. BMC Health Services Research. 2004; 4(1): 1. http://dx . doi .org/10. $1186 / 1472-6963-4-25$ 